\title{
ANÁLISE MULTIVARIADA NA COMPACTAÇÃO DE UM LATOSSOLO VERMELHO CULTIVADO COM MILHO(1)
}

\author{
Onã da Silva Freddi ${ }^{(2)}$, Antonio Sergio Ferraudo ${ }^{(3)} \&$ José \\ Frederico Centurion ${ }^{(4)}$
}

\begin{abstract}
RESUMO
Os solos submetidos aos sistemas de produção sem preparo estão sujeitos à compactação, provocada pelo tráfego de máquinas, tornando necessário o acompanhamento das alterações do ambiente físico, que, quando desfavorável, restringe o crescimento radicular, podendo reduzir a produtividade das culturas. O objetivo do trabalho foi avaliar o efeito de diferentes intensidades de compactação na qualidade física de um Latossolo Vermelho textura média, localizado em Jaboticabal (SP), sob cultivo de milho, usando métodos de estatística multivariada. $O$ delineamento experimental foi inteiramente casualizado, com seis intensidades de compactação e quatro repetições. Foram coletadas amostras indeformadas do solo nas camadas de $0,02-0,05,0,08-0,11$ e $0,15-0,18 \mathrm{~m}$ para determinação da densidade do solo (Ds), na camada de 0-0,20 m. As características da cultura avaliadas foram: densidade radicular, diâmetro radicular, matéria seca das raízes, altura das plantas, altura de inserção da primeira espiga, diâmetro do colmo e matéria seca das plantas. As análises de agrupamentos e componentes principais permitiram identificar três grupos de alta, média e baixa produtividade de plantas de milho, segundo variáveis do solo, do sistema radicular e da parte aérea das plantas. A classificação dos acessos em grupos foi feita por três métodos: método de agrupamentos hierárquico, método não-hierárquico $k$-means e análise de componentes principais. Os componentes principais evidenciaram que elevadas produtividades de milho estão correlacionadas com o bom crescimento da parte aérea das plantas, em condições de menor densidade do solo, proporcionando elevada produção de matéria seca das raízes, contudo, de pequeno diâmetro. A qualidade física do Latossolo Vermelho para o cultivo do milho foi assegurada até à densidade do solo de $1,38 \mathrm{Mg} \mathrm{m}^{-3}$.
\end{abstract}

Termos de indexação: densidade do solo, sistema radicular, produtividade, análise de agrupamentos, componentes principais.

\footnotetext{
(1) Projeto financiado pela FAPESP. Recebido para publicação em maio de 2007 e aprovado em janeiro de 2008.

(2) Pós-Doutorando em Agronomia pela Faculdade de Ciências Agrárias e Veterinárias, Universidade Estadual Paulista - UNESP. Departamento de Solos e Adubos. Via de Acesso Prof. Paulo Donato Castellane s/nº, CEP 14884-900 Jaboticabal (SP). Bolsista FAPESP. E-mail: ona_freddi@yahoo.com.br

(3) Professor Doutor, Departamento de Ciências Exatas. Faculdade de Ciências Agrárias e Veterinárias, UNESP. E-mail: fsajago@gmail.com

(4) Professor Adjunto, Departamento de Solos e Adubos. Faculdade de Ciências Agrárias e Veterinárias, UNESP. Bolsista CNPq. E-mail: jfcentur@fcav.unesp.br
} 


\title{
SUMMARY: MULTIVARIATE ANALYSIS OF A RED LATOSOL COMPACTION CULTIVATED WITH CORN
}

\begin{abstract}
Agricultural soils under no tillage systems are affected by soil compaction caused by machinery traffic, which can restrict root growth and reduce crop yields. The purpose of this study was to evaluate the effect of different compaction levels on the physical quality of a Red Latosol (Oxisol), sandy-loam, in the Jaboticabal county, São Paulo state, Brazil, under corn, using multivariate analysis. The experimental design was completely randomized with six compaction levels and four repetitions. Undisturbed soil samples were collected in the 0.02-0.05, 0.08-0.11 and 0.15-0.18 m layers to determine the bulk density. The following plant traits were evaluated: plant height, ear height, stem diameter, plant dry mass, root density, root diameter and root dry matter. By the clustering and principal component analysis three groups were identified of high, intermediate and low corn yield, based on variables of the soil, root system and aerial plant part. The groups were formed by the method of hierarchical clustering, $\mathrm{k}$-means and principal components analysis. The principal component analysis evidenced that high corn yields are correlated with a good development of the shoot under conditions of low bulk density, which in turn favored a high fine roots biomass. The physical quality of the Red Latosol was adequate for corn growth up to a bulk density of $1.38 \mathrm{Mg} \mathrm{m}^{-3}$.

Index terms: bulk density, root system, crop yield, cluster analysis, principal components analysis.
\end{abstract}

\section{INTRODUÇÃO}

Dentre os cereais cultivados no Brasil, o milho é o mais expressivo, com 35 milhões de toneladas de grãos produzidas em uma área aproximadamente de 12 milhões de hectares na safra 2004/2005 (FNP, 2006). Nos últimos anos, a produção brasileira de milho cresceu a uma taxa superior a $4 \%$ ao ano, sendo o principal componente desse crescimento a elevação da produtividade média (Couto et al., 2003). Os híbridos simples e triplos representam hoje cerca de $65 \%$ das opções para os produtores, mostrando uma tendência na agricultura brasileira, daí a necessidade de aprimorar os sistemas de produção utilizados, com vistas em melhor explorar o potencial genético dessas sementes (Cruz \& Pereira Filho, 2006).

Nos últimos anos, houve aumento substancial na utilização do sistema plantio direto, e, atualmente, mais de 12 milhões de hectares já são cultivados com este sistema, e cerca de 3 milhões de hectares ocupados com a cultura do milho (Coelho et al., 2004). Entretanto, segundo Maria et al. (1999) e Tavares Filho et al. (2001), o sistema plantio direto provoca compactação do solo, que está associada ao tráfego de máquinas agrícolas e ao não-revolvimento do solo.

Dentre os efeitos prejudiciais da compactação do solo, destacam-se: a redução da infiltração de água no solo, do movimento de ar, da retenção de água e da disponibilidade de nutrientes no solo, a redução da penetração e da ramificação das raízes por excessiva resistência mecânica e aeração deficiente, que podem prejudicar o crescimento e desenvolvimento vegetativo da parte aérea das plantas (Hakansson \& Voorhees, 1998), e, conseqüentemnte, a produção das culturas (Camargo \& Alleoni, 1997).
O crescimento e o desenvolvimento das raízes dependem das condições físicas e químicas do solo. Normalmente, as raízes apresentam crescimento vertical, mas, quando encontram uma camada compactada, podem modificar sua direção e forma de crescimento (Varsa et al., 1997). Segundo Benghough $\&$ Mullins (1990), o menor crescimento radicular em solos compactados ocorre por causa da menor taxa de elongação celular em virtude da diminuição da taxa de divisão celular do meristema. Dentre as modificações morfológicas nas raízes, provocadas pela restrição ao crescimento, estão o aumento do diâmetro e a diminuição do comprimento, tornando-as tortuosas (Silva \& Rosolem, 2002). Ivo \& Mielniczuk (1999) verificaram que, para o sistema plantio direto, na camada superficial $(0-0,05 \mathrm{~m})$, a densidade do comprimento radicular foi significativamente maior que no preparo convencional, sendo esta situação invertida na camada de $0,10-0,15 \mathrm{~m}$, e que, abaixo da camada trabalhada pelos implementos $(0,25-0,35 \mathrm{~m})$, as áreas preparadas apresentaram valores iguais de densidade radicular, quando comparadas às áreas de plantio direto. Os autores verificaram que as raízes não sofreram deflexão no ângulo normal de crescimento no preparo convencional por ocasião da etapa de ocupação dos primeiros $0,30 \mathrm{~m}$ do solo, o que foi observado para o plantio direto em decorrência da maior resistência à penetração. Os autores também verificaram que o raio médio das raízes no sistema plantio direto foi maior, quando comparado ao do preparo convencional em todas as camadas, resultante da maior resistência à penetração o que levou as raízes a sofrerem deformações morfológicas exteriorizadas pelo aumento de seu diâmetro.

Al-Adawi \& Reeder (1996), estudando os efeitos da compactação proporcionada por uma carreta de 
transporte de grãos com 9 e $11 \mathrm{Mg}$ por eixo, verificaram reduções de 24 e 43 \% na produtividade de grãos de milho, respectivamente. Albuquerque \& Reinert (2001) observaram que a restrição ao crescimento radicular imposta pelo aumento da densidade do solo, considerada pelos autores uma das principais propriedades físicas na caracterização da compactação do solo, reduziu a produtividade de grãos de milho em $1.169 \mathrm{Mg} \mathrm{ha}^{-1}$.

O crescimento do sistema radicular e da parte aérea das plantas é influenciado por várias propriedades físicas do solo, com complexas interações, tendo a interpretação isolada de variáveis do solo e da planta, na maioria dos estudos, dificultado o estabelecimento de relações funcionais do manejo do solo e o desenvolvimento e produção das culturas. O reconhecimento dessas interações e o fato de as culturas estarem sujeitas às suas interferências demonstraram a necessidade de quantificá-las na avaliação da influência das práticas de manejo sobre as condições físicas do solo (Tormena et al., 1998).

A análise estatística multivariada surgiu como importante ferramenta de obtenção de quantidade maior de informação que dificilmente seria gerada com o uso de métodos univariados (Beebe et al., 1998). Na estatística multivariada, o fenômeno depende de muitas variáveis, com isso não basta conhecer as variáveis isoladas, mas conhecê-las na sua totalidade, pois uma depende da outra e as informações são fornecidas pelo conjunto e não individualmente (Grobe, 2005). Segundo Fikdalski et al. (2007), os estudos que quantificam a qualidade do solo, de modo geral, apresentam inúmeras variáveis, as quais são descritas por meio de análises estatísticas univariadas, comprometendo, possivelmente, as interpretações e as conclusões destes, por não ser explorada a existência ou não da dependência entre as variáveis analisadas.

O objetivo do trabalho foi avaliar o efeito de diferentes intensidades de compactação na qualidade física do solo para o cultivo do milho usando métodos de estatística multivariada.

\section{MATERIAL E MÉTODOS}

O experimento foi realizado na Fazenda de Ensino e Pesquisa da Universidade Estadual Paulista (UNESP/FCAV), Jaboticabal (SP), situado nas coordenadas geográficas de $21^{\circ} 15$ ' 29 " de latitude Sul e $48^{\circ} 16$ ' 47 " de longitude Oeste, e altitude média de $614 \mathrm{~m}$. O clima é do tipo Cwa, segundo o sistema de classificação de Köppen, com verão quente e inverno seco, precipitação pluvial média anual de $1.428 \mathrm{~mm}$ e temperatura média de $21^{\circ} \mathrm{C}$. A área utilizada para o experimento vinha sendo utilizada no sistema de preparo convencional com a sucessão anual de milho e soja.
O solo da área experimental é um Latossolo Vermelho distrófico típico textura média $\mathrm{A}$ moderado caulinítico e hipoférrico (LVd). A composição granulométrica do solo foi determinada em amostras deformadas, na camada de $0-0,20 \mathrm{~m}$, por meio de dispersão com $\mathrm{NaOH}\left(0,1 \mathrm{~mol} \mathrm{~L}^{-1}\right)$ e agitação lenta durante $16 \mathrm{~h}$, sendo o teor de argila obtido pelo método da pipeta (Gee \& Bauder, 1986). O solo apresentou, na camada de $0-0,20 \mathrm{~m}$, valores médios de $323 \mathrm{~g} \mathrm{~kg}^{-1}$ de argila, 45 de silte e 632 de areia.

O delineamento experimental foi o inteiramente casualizado, constituído por seis intensidades de compactação e quatro repetições. Toda parcela experimental apresentou cinco linhas de milho com seis metros de comprimento, considerando-se área útil as três linhas centrais e desprezando-se um metro e meio de cada extremidade. Na análise multivariada, considerou-se cada parcela como um acesso, sendo cada acesso representado pelo valor da produtividade de grãos de milho, utilizando oito variáveis para as análises, formando uma matriz de 24 linhas (acessos) por oito colunas (variáveis). Tanto para densidade do solo como para as características do sistema radicular, utilizou-se a média da camada de $0-0,20 \mathrm{~m}$ para as análises estatísticas.

A análise química de rotina para fins de fertilidade seguiu o método proposto por Raij et al. (1987). No mês de setembro de 2004, foi aplicado calcário para elevação da saturação por bases a $60 \%$, incorporandoo com gradagem niveladora até $0,12 \mathrm{~m}$ de profundidade. Antes da instalação do experimento, toda a área foi escarificada a $0,30 \mathrm{~m}$ de profundidade seguida de uma gradagem aradora.

Os tratamentos foram: $\mathrm{T}_{1}=$ solo não trafegado; $\mathrm{T}_{2}=1$ passada de um trator de pneus de $4 \mathrm{Mg}$ com potência de $70 \mathrm{cv}$ e tração $4 \times 2 ; \mathrm{T}_{3}=$ uma passada de um trator de pneus de $11 \mathrm{Mg}$ com potência de $150 \mathrm{cv}$ e tração $4 \times 4 ; \mathrm{T}_{4}=$ duas passadas de um trator de pneus de $11 \mathrm{Mg}$ com potência de $150 \mathrm{cv}$ e tração $4 \mathrm{x} 4$, $\mathrm{T}_{5}=$ quatro passadas de um trator de pneus de $11 \mathrm{Mg}$ com potência de $150 \mathrm{cv}$ e tração $4 \times 4 \mathrm{e} \mathrm{T}_{6}=$ seis passadas de um trator de pneus de $11 \mathrm{Mg}$ com potência de $150 \mathrm{cv}$ e tração 4 x 4 . Os tratores trafegaram por toda parcela, no sentido do declive da área, de forma que os pneus comprimissem áreas paralelas entre si. O número de vezes que os tratores trafegaram variou conforme o tratamento, sendo o tráfego sobreposto ao anterior. Com isso, toda área de cada parcela foi trafegada com número igual de vezes. O conteúdo de água no solo durante a compactação esteve próximo à capacidade de campo $\left(0,16 \mathrm{~kg} \mathrm{~kg}^{-1}\right)$.

No dia 22 de novembro de 2004, utilizando uma semeadora-adubadora de plantio direto, foi semeado o híbrido triplo de milho Master, de ciclo precoce, no espaçamento de 0,9 m nas entrelinhas e de oito a 10 sementes por metro, adubado com $0,3 \mathrm{Mg} \mathrm{ha}^{-1}$ da fórmula 10-20-20, para obtenção da produtividade esperada de 6 a $8 \mathrm{Mg} \mathrm{ha}^{-1}$, segundo Raij et al. (1997). Após 15 dias da emergência das plântulas, foi feito o 
desbaste para cinco plantas por metro. A adubação de cobertura foi realizada 28 dias após a emergência das plântulas, utilizando $0,3 \mathrm{Mg} \mathrm{ha}^{-1}$ de sulfato de amônio, aplicado sem incorporação, quando as plantas estavam com sete a oito folhas.

Após a semeadura, foram coletadas 36 amostras indeformadas do solo, na entrelinha da cultura, por tratamento, com cilindros de 54,29 x 10-6 $\mathrm{m}^{3}(0,03 \mathrm{~m}$ de altura e 0,048 $\mathrm{m}$ de diâmetro), nas camadas de 0,02-0,05; 0,08-0,11 e 0,15-0,18 m, para determinação da densidade do solo, segundo método proposto por Blake \& Hartge (1986), sendo retirado um total de 216 amostras no experimento.

No estádio do pendoamento da cultura do milho, período no qual, segundo Mengel \& Barber (1974), o sistema radicular do milho alcança a máxima extensão, foram retiradas quatro amostras de $0,20 \mathrm{~m}$ no sentido da linha $\mathrm{x}$ 0,10 $\mathrm{m}$ no sentido da entrelinha, junto ao eixo principal das plantas de milho, nas camadas de 0-0,10 e 0,10-0,20 m, em cada tratamento. Em seguida, as raízes foram separadas do solo por lavagem em água corrente, utilizando peneira de abertura de malha de 0,005 m. As imagens das raízes foram digitalizadas em um "scanner" de leitura ótica, na resolução de 400 dpi, e analisadas quanto à densidade, superfície e diâmetro radicular pelo software "Delta-T Scan", utilizando o método de Harris \& Campbell (1989). Na seqüência, as amostras foram secas em estufa $\mathrm{a} \pm 65^{\circ} \mathrm{C}$ até peso constante, para determinação da matéria seca das raízes.

No estádio de pendoamento do milho, foram determinados também a altura das plantas, a altura de inserção da primeira espiga e o diâmetro do segundo internódio do colmo, em cinco plantas por parcela na área útil. A altura das plantas foi medida entre o solo e a inserção da base do pendão, e o diâmetro do colmo foi determinado utilizando a média de duas leituras do segundo internódio do colmo por meio de paquímetro digital. Avaliou-se também a matéria seca mediante a coleta de quatro plantas por repetição cortadas junto ao solo. Foram separados caules, folhas, pendões e espigas, e levados à estufa ventilada, a aproximadamente $65^{\circ} \mathrm{C}$ até peso constante. A produtividade de grãos de milho foi obtida extrapolando a produção de grãos da área útil da parcela para um hectare, considerando-se a umidade padrão de $13 \%$.

Os dados de densidade, diâmetro e matéria seca radicular foram transformados em $\sqrt{\mathrm{x}+0,5}$ para satisfazer as hipóteses estatísticas de homocedasticidade das variâncias (teste de Levene; $p$ > 0,05) e normalidade dos resíduos (teste de Shapiro-Wilk; $p>0,05$ ). Foram aplicados três métodos estatísticos multivariados, visando classificar os acessos em grupos: análise de agrupamentos hierárquica, análise de agrupamentos não-hierárquica $k$-means e análise de componentes principais. Todas as análises multivariadas foram realizadas após a padronização das variáveis em que cada uma ficou com média 0 e variância 1.
A análise de agrupamentos hierárquica (Sneath \& Sokal, 1973) foi realizada calculando-se a distância euclidiana entre os acessos, para o conjunto das sete variáveis, e utilizando o algoritmo de Ward para a obtenção dos agrupamentos de acessos similares. O resultado da análise foi apresentado em forma gráfica (dendrograma) que auxiliou na identificação dos agrupamentos dos acessos.

A identificação dos acessos nos grupos também foi feita pelo $k$-means (Hair, 2005) que pertence à classe dos métodos de agrupamentos não-hierárquicos e não supervisionados. Este método minimiza a variância dos acessos dentro de cada grupo.

A análise de componentes principais permite condensar a maior quantidade da informação original contida em $p$ variáveis ( $p=7$, neste estudo) em duas variáveis latentes ortogonais denominadas componentes principais, que são combinações lineares das variáveis originais criadas com os dois maiores autovalores da matriz de covariância dos dados (Hair, 2005). Desta forma, o conjunto inicial de sete variáveis passou a ser caracterizado por duas novas variáveis latentes, o que possibilitou sua localização em figuras bidimensionais (ordenação dos acessos por componentes principais). A adequação desta análise é verificada pela quantidade da informação total das variáveis originais retida pelos componentes principais que mostram autovalores superiores à unidade (Kaiser, 1958). Autovalores inferiores à unidade não dispõem de informação relevante.

Todas as análises estatísticas foram processadas no software STATISTICA versão 7.0 (Statsoft, 2004).

\section{RESULTADOS E DISCUSSÃO}

O dendrograma obtido pela análise de agrupamentos é apresentado na figura 1. Cada vez que se obtém variação expressiva nos valores de distância euclidiana entre os acessos, para o conjunto de variáveis consideradas, é possível fazer uma divisão de grupos. No presente trabalho, a variação de 6,5 para 12,5 (Figura 2) permitiu uma divisão exata dos acessos em três grupos. Este salto foi adotado, admitindo-se formação de três grupos: I, II e III (Figura 1). Essa divisão mostrou um resultado muito importante que foi a ordenação dos acessos segundo a produtividade. No grupo I, ficaram concentrados os acessos com alta produtividade, no grupo I, os acessos com média produtividade e, no grupo III, os acessos com baixa produtividade, segundo as características agronômicas do milho e densidade do solo.

Considerando o número de grupos igual a três, aplicou-se o método de agrupamentos $k$-means para a confirmação da ordenação obtida na análise de agrupamentos hierárquica. Os resultados confirmaram a ordenação e, ainda, conforme análise de variância (Quadro 1), todas as variáveis foram 


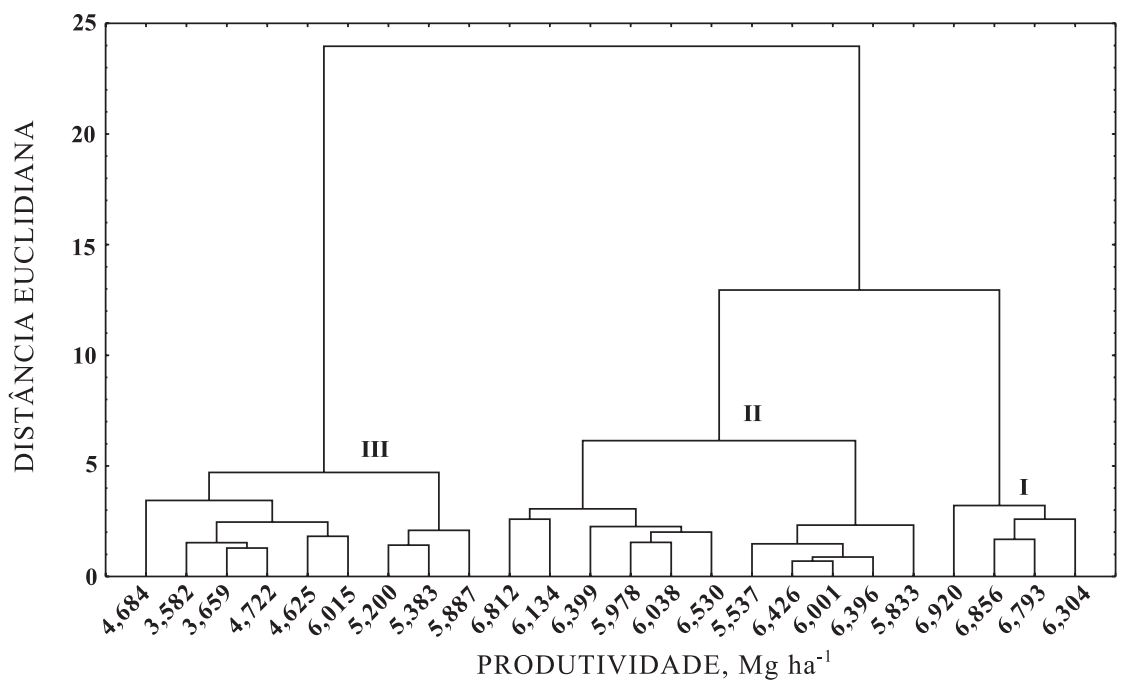

Figura 1. Dendrograma resultante da análise hierárquica de agrupamentos mostrando a formação de grupos segundo a densidade radicular, superfície radicular, diâmetro radicular, matéria seca das raízes, altura das plantas, altura de inserção da primeira espiga, diâmetro do colmo, matéria seca das plantas e densidade do solo.

importantes nessa ordenação $(\mathrm{p}<0,05)$. As médias de cada variável dentro de cada grupo foram comparadas pelo teste de Tukey a $5 \%$ (Quadro 2).

O grupo I (acessos com alta produtividade) ficou caracterizado pela menor densidade do solo, que variou de 1,287 a $1,381 \mathrm{Mg} \mathrm{m}^{-3}$, proporcionando maior matéria seca de raízes e densidade e diâmetro radicular intermediários aos outros grupos (Quadro 2). A maior matéria seca das raízes pode ser justificada pela maior quantidade de raízes finas explorando todo o volume da camada de $0-0,20 \mathrm{~m}$. As plantas desse grupo também apresentaram maior altura, inserção da espiga, diâmetro do colmo e produção de matéria seca. Nota-se que a baixa densidade do solo nesse grupo não restringiu o crescimento radicular, o que promoveu

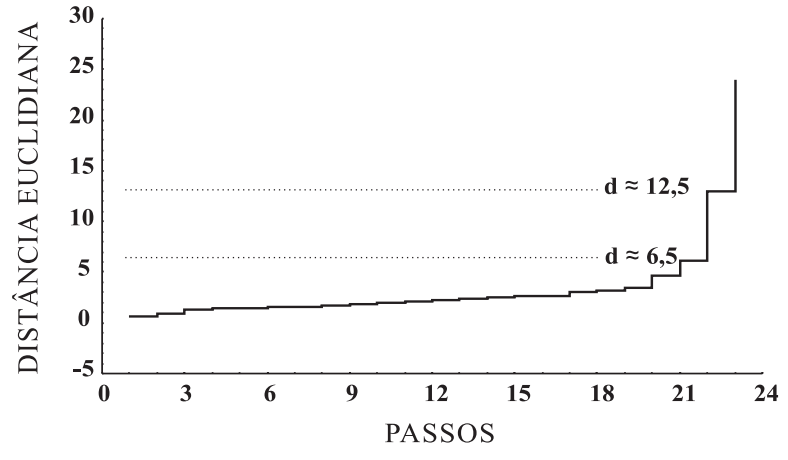

Figura 2. Representação da variação expressiva da distância euclidiana entre as variáveis consideradas que permitiu a separação de grupos.

Quadro 1. Análise de variância para cada variável dos grupos formados pela análise não-hierárquica de agrupamentos $k$-means

\begin{tabular}{|c|c|c|c|c|c|c|}
\hline Variável $^{(1)}$ & $\begin{array}{c}\text { Somade } \\
\text { quadrados } \\
\text { entre grupos }\end{array}$ & $\begin{array}{l}\text { Graus de } \\
\text { liberdade }\end{array}$ & $\begin{array}{c}\text { Soma de } \\
\text { quadrados } \\
\text { dentrodos grupos }\end{array}$ & $\begin{array}{l}\text { Graus de } \\
\text { liberdade }\end{array}$ & Fc & Prob. \\
\hline DSR & 17,71225 & 2 & 5,28775 & 21 & 35,1716 & $<0,0001$ \\
\hline MSR & 14,57233 & 2 & 8,42767 & 21 & 18,1556 & $<0,0001$ \\
\hline DIAR & 14,79425 & 2 & 8,20575 & 21 & 18,9306 & $<0,0001$ \\
\hline ALPL & 14,55002 & 2 & 8,44998 & 21 & 18,0800 & $<0,0001$ \\
\hline ALESP & 14,62936 & 2 & 8,37065 & 21 & 18,3508 & $<0,0001$ \\
\hline DIACO & 12,17311 & 2 & 10,82689 & 21 & 11,8056 & 0,0004 \\
\hline MS & 10,82655 & 2 & 12,17345 & 21 & 9,3383 & 0,0013 \\
\hline DS & 22,09566 & 2 & 0,90434 & 21 & 256,5465 & $<0,0001$ \\
\hline
\end{tabular}

(1) DSR: densidade do comprimento radicular, MSR: matéria seca das raízes, DIAR: diâmetro radicular, ALPL: altura de plantas, ALESP: altura de inserção da espiga, DIACO: diâmetro do colmo, MS: matéria seca das plantas e DS: densidade do solo. Fc: valor da F calculado. Prob.: probabilidade de se obter um valor de F $\geq$ Fc. 
o bom crescimento e desenvolvimento da parte aérea das plantas atingindo maiores produtividades, concordando com Magalhães (2003), segundo o qual a redução da massa vegetativa ocasiona diminuição na capacidade fotossintética, alterando diretamente a produção de grãos.

O grupo II (acessos com média produtividade) apresentou densidade do solo intermediária à dos outros grupos, que variou de 1,600 a 1,715 $\mathrm{Mg} \mathrm{m}^{-3}$, alterando as características do sistema radicular e da parte aérea das plantas (Quadro 2). Verificou-se que o sistema radicular apresentou menor densidade e matéria seca das raízes e que o diâmetro das raízes não foi alterado em relação ao grupo I com o aumento da densidade do solo, o que resultou em diminuição da altura das plantas, altura de inserção da espiga, entretanto, não ocorreu alteração do diâmetro do colmo e matéria seca das plantas.
O grupo III (acessos com baixa produtividade) apresentou a maior densidade do solo, que variou de 1,724 a $1,763 \mathrm{Mg} \mathrm{m}^{-3}$, resultando em maior densidade de radicular, considerando a elevada matéria seca das raízes e o maior diâmetro radicular, resultando em plantas com menor altura, diâmetro do colmo e, conseqüentemente, produção de matéria seca em relação aos outros grupos (Quadro 2), concordando com Hankansson \& Voorhees (1998), que o menor crescimento da parte aérea em solos compactados ocorre por causa da redução da penetração e da ramificação das raízes, em conseqüência do aumento da compactação do solo, e da menor infiltração e movimento da água e disponibilidade de nutrientes no solo. Para Letey (1985), o aumento da compactação do solo causa o crescimento reduzido do sistema radicular que, através de sinais hormonais enviados pelas raízes, reduz o crescimento da parte aérea da

Quadro 2. Médias não padronizadas das características agronômicas do milho e densidade do solo em cada grupo pela análise de agrupamentos $k$-means

\begin{tabular}{|c|c|c|c|c|c|c|c|c|c|}
\hline Grupo & Acessos & $\operatorname{DSR}^{(1)}$ & $\operatorname{MSR}^{(1)}$ & $\operatorname{DIAR}^{(1)}$ & ALPL & ALESP & DIACO & MS & DS \\
\hline \multirow{5}{*}{$3 \pi$} & $\mathrm{Mg} \mathrm{ha}^{-1}$ & $\mathrm{~cm} \mathrm{~cm}^{-3}$ & $\mathrm{mg} \mathrm{cm}^{-3}$ & $\mathrm{~mm}$ & 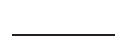 & $-\mathrm{cm}$ & - & $\mathrm{Mg} \mathrm{ha}^{-1}$ & $\mathrm{Mg} \mathrm{m}^{-3}$ \\
\hline & 6,304 & 0,845 & 0,539 & 0,781 & 256,4 & 166,8 & 1,865 & 7,115 & 1,381 \\
\hline & 6,793 & 0,828 & 0,487 & 0,767 & 251,0 & 145,8 & 1,970 & 8,369 & 1,321 \\
\hline & 6,856 & 0,779 & 0,478 & 0,748 & 250,0 & 159,8 & 1,885 & 8,240 & 1,287 \\
\hline & 6,920 & 0,889 & 0,462 & 0,663 & 237,6 & 151,8 & 1,770 & 7,150 & 1,306 \\
\hline \multirow[t]{6}{*}{ Média } & & $0,835 \mathrm{~b}$ & $0,491 \mathrm{a}$ & $0,740 \mathrm{~b}$ & $248,8 \mathrm{a}$ & $156,1 \mathrm{a}$ & $1,873 \mathrm{a}$ & $7,719 a$ & $1,324 \mathrm{c}$ \\
\hline & 5,833 & 0,644 & 0,342 & 0,690 & 229,6 & 144,2 & 1,656 & 7,064 & 1,632 \\
\hline & 6,396 & 0,781 & 0,369 & 0,681 & 229,4 & 140,0 & 1,750 & 5,980 & 1,659 \\
\hline & 6,001 & 0,782 & 0,376 & 0,660 & 229,4 & 140,0 & 1,750 & 6,753 & 1,683 \\
\hline & 6,426 & 0,755 & 0,391 & 0,686 & 230,0 & 138,6 & 1,800 & 6,599 & 1,713 \\
\hline & 5,537 & 0,713 & 0,369 & 0,687 & 228,8 & 133,6 & 1,850 & 7,035 & 1,715 \\
\hline \multirow[t]{6}{*}{ II } & 6,530 & 0,741 & 0,362 & 0,640 & 237,2 & 142,4 & 1,882 & 7,803 & 1,628 \\
\hline & 6,038 & 0,632 & 0,406 & 0,733 & 241,6 & 148,4 & 2,006 & 8,526 & 1,619 \\
\hline & 5,978 & 0,768 & 0,419 & 0,705 & 242,6 & 148,0 & 1,882 & 8,226 & 1,657 \\
\hline & 6,399 & 0,641 & 0,398 & 0,644 & 239,8 & 156,4 & 1,780 & 8,436 & 1,672 \\
\hline & 6,134 & 0,652 & 0,437 & 0,661 & 246,0 & 150,2 & 1,796 & 6,238 & 1,600 \\
\hline & 6,812 & 0,534 & 0,353 & 0,741 & 237,4 & 140,4 & 1,910 & 6,700 & 1,650 \\
\hline \multirow[t]{5}{*}{ Média } & & $0,695 \mathrm{c}$ & $0,384 b$ & $0,684 b$ & $235,6 \mathrm{~b}$ & $143,8 \mathrm{~b}$ & $1,824 \mathrm{a}$ & $7,215 \mathrm{a}$ & $1,657 \mathrm{~b}$ \\
\hline & 5,887 & 1,035 & 0,518 & 0,864 & 235,4 & 137,0 & 1,770 & 7,619 & 1,725 \\
\hline & 5,383 & 1,008 & 0,497 & 0,899 & 226,2 & 131,4 & 1,720 & 6,048 & 1,724 \\
\hline & 5,200 & 0,943 & 0,458 & 0,837 & 232,2 & 137,0 & 1,726 & 6,035 & 1,754 \\
\hline & 6,015 & 0,903 & 0,387 & 0,789 & 222,6 & 135,0 & 1,680 & 4,922 & 1,726 \\
\hline \multirow[t]{5}{*}{ III } & 4,625 & 0,849 & 0,433 & 0,709 & 213,4 & 133,6 & 1,606 & 5,437 & 1,741 \\
\hline & 4,722 & 0,998 & 0,479 & 0,774 & 226,6 & 138,2 & 1,635 & 5,442 & 1,756 \\
\hline & 3,659 & 0,893 & 0,449 & 0,781 & 225,2 & 135,6 & 1,650 & 6,419 & 1,763 \\
\hline & 3,582 & 1,027 & 0,445 & 0,824 & 221,4 & 133,2 & 1,551 & 5,860 & 1,756 \\
\hline & 4,684 & 1,018 & 0,541 & 0,819 & 213,8 & 124,0 & 1,686 & 4,661 & 1,744 \\
\hline Média & & $0,964 \mathrm{a}$ & $0,467 \mathrm{a}$ & $0,811 \mathrm{a}$ & $224,1 \mathrm{c}$ & $133,9 \mathrm{c}$ & $1,669 \mathrm{~b}$ & $5,827 \mathrm{~b}$ & $1,743 \mathrm{a}$ \\
\hline Média geral & & 0,819 & 0,433 & 0,741 & 233,5 & 142,1 & 1,774 & 6,778 & 1,634 \\
\hline $\mathrm{CV}(\%)$ & & 8,72 & 8,64 & 6,16 & 3,00 & 4,37 & 1,77 & 12,67 & 1,91 \\
\hline
\end{tabular}

${ }^{(1)}$ Médias transformadas em $\sqrt{\mathrm{x}+0,5}$. DSR: densidade do comprimento radicular, MSR: matéria seca das raízes, DIAR: diâmetro radicular, ALPL: altura de plantas, ALESP: altura de inserção da espiga, DIACO: diâmetro do colmo, MS: matéria seca das plantas e DS: densidade do solo. Médias seguidas pela mesma letra, na coluna, não diferem entre si pelo teste de Tukey a 5 \%. 
planta. Segundo Foloni et al. (2003), o diâmetro médio das plantas de milho aumentou significativamente com a compactação do Latossolo Vermelho, podendo o engrossamento das raízes das plantas de milho na camada compactada ser um indicativo de que esta espécie tem pouco potencial para estabelecer o seu sistema radicular em solos compactados.

A figura 3 indica as médias padronizadas das características agronômicas do milho e densidade do solo para cada grupo, segundo análise de agrupamentos pelo método $k$-means. Observa-se que, na condição de baixa densidade do solo, ocorreu a maior matéria seca das raízes com densidade e diâmetro radiculares intermediários às outras condições, o que permitiu maior produtividade. Com o aumento da compactação para um nível intermediário, pode-se notar diminuição da matéria seca, densidade e diâmetro radicular, bem como pequena redução na produtividade. Já na condição de maior densidade do solo, em relação ao grupo II, as raízes responderam com aumento da matéria seca das raízes e principalmente da densidade e diâmetro radiculares, que foram superiores aos do grupo I, resultando na menor produtividade. Observa-se que, com o aumento da densidade do solo, houve redução da altura das plantas, da inserção da primeira espiga, do diâmetro do colmo e da matéria seca (Figura 3). Entretanto, para o diâmetro do colmo e matéria seca das plantas, houve pequena redução do grupo I para o grupo II.

A análise de componentes principais permitiu uma única distribuição dos acessos (componente principal $1 \mathrm{x}$ componente principal 2), visto que somente dois autovalores foram superiores a um: maior autovalor 4,34 (componente com melhor retenção da variabilidade original) e segundo maior autovalor 2,10 (componente com melhor retenção da

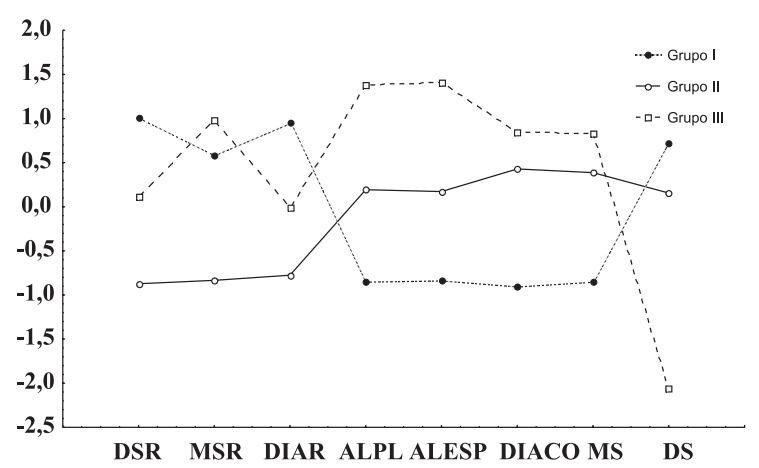

Figura 3. Médias padronizadas das características agronômicas do milho e densidade do solo para cada grupo, segundo análise de agrupamentos não-hierárquica $\boldsymbol{k}$-means. DSR: densidade do comprimento radicular, MSR: matéria seca das raízes, DIAR: diâmetro radicular, ALPL: altura de plantas, ALESP: altura de inserção da espiga, DIACO: diâmetro do colmo, MS: matéria seca das plantas e DS: densidade do solo. variabilidade excluindo a variabilidade retida no primeiro componente). Os dois componentes principais juntos possibilitaram uma ordenação bidimensional dos acessos e das variáveis, o que permitiu a construção de um gráfico biplot (Figura 4). A quantidade da informação total das variáveis originais, retida pelos dois componentes principais, foi de 80,60\% [54,21\% (primeiro componente principal) $+26,36 \%$ (segundo componente principal)] (Figura 4).

A ordenação dos acessos segundo os dois primeiros componentes principais confirma a ordenação dos acessos em três grupos obtida pelas análises de agrupamentos, hierárquica e não-hierárquica (Figura 4).

A representação gráfica e a correlação das variáveis nos componentes principais (Figura 4 e Quadro 3) permitiram caracterizar as variáveis que mais discriminaram na formação dos grupos I, II e III. As variáveis altura das plantas $(-0,89)$, altura de inserção da primeira espiga $(-0,86)$, matéria seca das plantas $(-0,85)$ e diâmetro do colmo $(-0,83)$ são responsáveis pela discriminação dos grupos I e II, localizados à esquerda de CP1 (correlações negativas), enquanto as variáveis diâmetro radicular $(0,55)$, densidade radicular $(0,71)$ e densidade do solo $(0,73)$ são responsáveis pela discriminação do grupo III, localizado à direita (correlações positivas). Assim, os grupos I e II (maior produtividade) são caracterizados por plantas mais altas, com maior altura de inserção da espiga, maior diâmetro do colmo e com maior produção de matéria seca, enquanto o grupo III

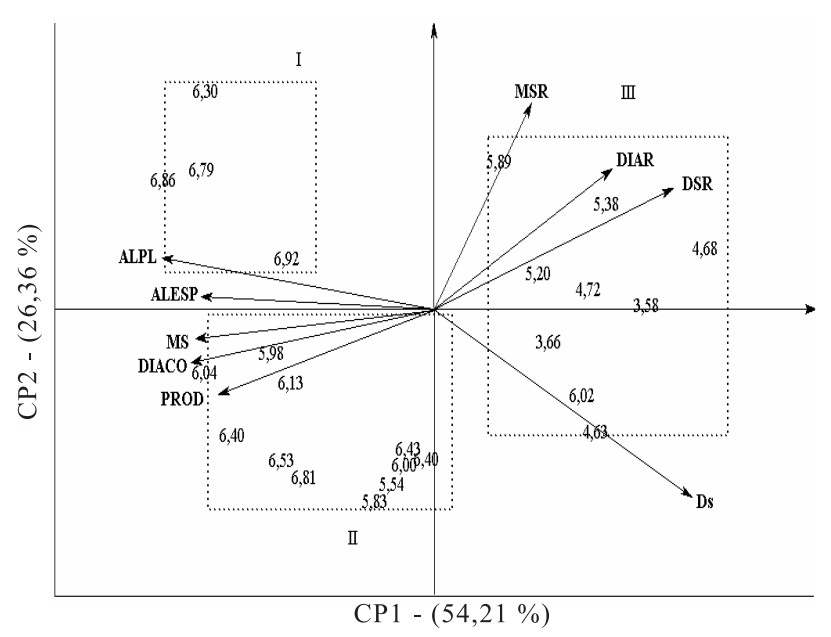

Figura 4. Dispersão (gráfico biplot) da produtividade de milho $\left(\mathrm{Mg} \mathrm{ha}^{-1}\right)$ em diferentes condições de compactação do Latossolo Vermelho de textura média. PROD: produtividade, DSR: densidade radicular, MSR: matéria seca das raízes, DIAR: diâmetro radicular, ALPL: altura de plantas, ALESP: altura de inserção da espiga, DIACO: diâmetro do colmo, MS: matéria seca das plantas e DS: densidade do solo. 
Quadro 3. Correlação entre cada componente principal e densidade do Latossolo Vermelho de textura média, características agronômicas do milho

\begin{tabular}{lcc}
\hline \multicolumn{1}{c}{ Variável } & CP1 & CP2 \\
\hline & 0,709568 & 0,620645 \\
Densidade radicular & 0,213574 & 0,930325 \\
Matéria seca das raízes & 0,556891 & 0,668758 \\
Diâmetro radicular & $-0,893439$ & 0,358605 \\
Altura das plantas & $-0,857585$ & 0,245537 \\
Altura de inserção $1^{\text {a espiga }}$ & $-0,828412$ & 0,090759 \\
Diâmetro do colmo & $-0,848123$ & 0,084733 \\
Matéria seca das plantas & 0,733612 & $-0,454599$ \\
Densidade do solo & $-0,785510$ & $-0,038404$ \\
Produtividade &
\end{tabular}

CP1: componente principal 1; CP2: componente principal 2.

caracteriza-se por plantas com maior diâmetro de raiz, maior densidade radicular e solo com maior compactação.

No segundo componente principal, somente a variável matéria seca das raízes, com correlação positiva de 0,93, discriminou aqueles acessos localizados na parte superior do gráfico biplot (Figura 4), indicando que esses acessos apresentam maior matéria seca de raízes do que aqueles localizados na parte inferior.

Logo, pode-se afirmar, com base nas três análises exploratórias de dados, que realmente houve a separação de três níveis de produtividade de milho, resultantes do efeito do tráfego de tratores, que determinou diferentes condições de densidade do solo, crescimento radicular e crescimento aéreo da cultura do milho.

\section{CONCLUSÕES}

1. Houve efeito de diferentes intensidades de compactação na qualidade física de um Latossolo Vermelho textura média, e as análises de agrupamentos hierárquica e não-hierárquica e componentes principais permitiram ordenar acessos em três grupos de alta, média e baixa produtividade de plantas de milho, segundo variáveis do solo, do sistema radicular e da parte aérea das plantas.

2. A análise de componentes principais indicou que elevadas produtividades de milho mostravam-se correlacionadas com o bom crescimento da parte aérea das plantas, em condições de menor densidade do solo, proporcionando elevada produção de matéria seca das raízes, entretanto, de pequeno diâmetro.

3. A qualidade física do Latossolo Vermelho de textura média para o cultivo do milho, avaliada por meio de análises multivariadas, foi assegurada até o valor de densidade do solo de $1,38 \mathrm{Mg} \mathrm{m}^{-3}$.

4. A classificação multivariada da qualidade física do solo pode contribuir para melhorar o planejamento e controle da produtividade de milho, bem como a execução das atividades de manejo do solo.

\section{LITERATURA CITADA}

AL-ADAWI, S.S. \& REEDER, R.C. Compaction and subsoiling effects on corn and soybean yields and soil physical properties. Am. Soc. Agric. Eng., 39:1641-1649, 1996.

ALBUQUERQUE, J.A. \& REINERT, D.J. Densidade radicular do milho considerando os atributos de um solo com horizonte B textural. R. Bras. Ci. Solo, 25:539-549, 2001.

BEEBE, K.R.; PELL, R.J. \& SEASHOLT, M.B. Chemometrics: A practical guide. New York, John Wiley \& Sons, 1998. 348 p.

BENGOUGH, A.G. \& MULLINS, C.E. Mechanical impendance to root growth: A review of experimental techniques and root growth response. J. Soil Sci., 41:341-358, 1990.

BLAKE, G.R. \& HARTGE, K.H. Bulk density. In: KLUTE, A., ed. Methods of soil analysis. Madison, American Society of Agronomy, 1986. p.377-382.

CAMARGO, O. A. \& ALLEONI, L. R. F. Compactação do solo e o desenvolvimento das plantas. Piracicaba, Escola Superior de Agricultura Luiz de Queiroz, 1997. 132p.

COELHO, A.M.; CRUZ, J.C. \& PEREIRA FILHO, I.A. Desafios para obtenção de altas produtividades. Sete Lagoas, Empresa Brasileira de Pesquisa Agropecuária, 2004. 20p.

COUTO, L.; RESENDE, M. \& ALBUQUERQUE, P.E.P. Importância do milho irrigado. In: RESENDE, M.; ALBUQUERQUE, P.E.P. \& COUTO, L., eds. A cultura do milho irrigado. Brasília, Embrapa Informação Tecnológica, 2003. p.17-30.

CRUZ, J.C. \& PEREIRA FILHO, I.A. Milho: Cultivares para 2005/2006. Disponível em: <http://www.cnpms.embrapa.br/ milho/cultivares/index.php $>$. Acesso em: 25 de out. de 2006.

FIDALSKI, J.; TORMENA, C.A. \& SCAPIM, C.A. Espacialização vertical e horizontal dos indicadores de qualidade para um Latossolo Vermelho. R. Bras. Ci. Solo, 27:9-19, 2007.

FNP Consultoria \& Comércio. Milho. In: NAKAMAE, I.J., ed. Agrianual 2006. São Paulo, Argos, 2006. p.396-397.

FOLONI, J.S.S.; CALONEGO, J.C. \& LIMA, S.L. Efeito da compactação do solo no desenvolvimento aéreo e radicular de cultivares de milho. Pesq. Agropec. Bras., 38:947-953, 2003.

GEE, G.W. \& BAUDER, J.W. Particle-size analysis. In: KLUTE, A., ed. Methods of soil analysis: Part 1 - Physical and mineralogical methods. Madison, American Society of Agronomy, 1986. p.383-409. 
GROBE, J.R. Aplicações da estatística multivariada na análise de resultados em experimentos com solos e animais. Curitiba, Universidade Federal do Paraná, 2005. 145p. (Tese de Mestrado)

HAIR, J.F.; ANDERSON, R.E.; TATHAM, R.L. \& BLACK, W. Análise multivariada de dados. Porto Alegre, Bookman, 2005.

HAKANSSON, I. \& VOORHEES, W.B. Soil compaction. In: LAL, R.; BLUM, W.H.; VALENTINE, C. \& STEWARD, B.A., eds. Methods for assessment of soil degradation. Boca Raton, CRS Press, 1998. p.167-179.

HARRIS, G.A. \& CAMPBELL, G.S. Automated quantification o roots using a simple image analyzer. Agron. J., 81:935938, 1989

IVO, W.M.P.M \& MIELNICZUK, J. Influência da estrutura do solo na distribuição e na morfologia do sistema radicular do milho sob três métodos de preparo. R. Bras. Ci. Solo, 23:135-143, 1999.

KAISER, H.F. The varimax criterion for analytic rotation in factor analysis. Psychometrika, 23:187-200, 1958.LETEY, J. Relationship between soil physical properties and crop production. Adv. Soil Sci., 1:277-293, 1985.

MAGALHÃES, P.C. Aspectos fisiológicos da cultura do milho irrigado. In: RESENDE, M.; ALBUQUERQUE, P.E.P. \& COUTO, L., eds. A cultura do milho irrigado. Brasília, Embrapa Informação Tecnológica, 2003. p.43-67.

MARIA, I.C.; CASTRO, O.M. \& SOUZA DIAS, H. Atributos físicos do solo e crescimento radicular de soja em Latossolo Roxo sob diferentes métodos de preparo do solo. R. Bras. Ci. Solo, 23:703-709, 1999.
MENGEL, D.B. \& BARBER, S.A. Development and distribution of the corn root under field conditions. Agron. J., 66:341344,1974

RAIJ, B.van; CANTARELLA, H.; QUAGGIO, J.A. \& FURLANI, A.M.C. Recomendações de adubação e calagem para o Estado de São Paulo. Campinas, Instituto Agronômico/ Fundação IAC, 1997. 285p.

RAIJ, B.van; QUAGGIO, J.A.; CANTARELLA, H.; FERREIRA, M.; LOPES, A.S. \& BATAGLIA, O.C. Análise química do solo para fins de fertilidade. Campinas, Fundação Cargill, 1987. 170p.

SILVA, R.H. \& ROSOLEM, C.A. Crescimento radicular de soja em razão da sucessão de cultivos e da compactação do solo. Pesq. Agropec. Bras., 37:855-860, 2002.

SNEATH, P.H. \& SOKAL, R.R. Numerical taxonomy: The principles and practice of numerical classification. San Francisco, W.H. Freeman, 1973. 573p.

STATSOFT, Inc. (2004). STATISTICA (data analysis software system), version 7. Disponível em: <www.statsoft.com>.

TAVARES FILHO, J.; BARBOSA, G.M.; GUIMARÃES, M.F. \& FONSECA, I.C.B. Resistência à penetração e desenvolvimento do sistema radicular do milho (Zea mays) sob diferentes sistemas de manejo em um Latossolo Roxo. R. Bras. Ci. Solo, 25:725-730, 2001.

TORMENA, C.A.; SILVA, A.P. \& LIBARDI, P.L. Caracterização do intervalo hídrico ótimo de um Latossolo Roxo sob plantio direto. R. Bras. Ci. Solo, 22:573-581, 1998.

VARSA, E.C.; CHONG, S.K.; ABOLAJI, J.O.; FARQUHAR, D.A. \& OLSEN, F.J. Effect of deep tillage on soil physical characteristics and corn (Zea mays L.) root growth and production. Soil Till. Res., 43:219-228, 1997. 